\title{
Mengikisnya Nilai Persatuan dan Kesatuan Pada Masyarakat
}

\author{
Else Auvi Dalilah \\ Iik Strada Indonesia \\ elseauvi0@gmail.com
}

\begin{abstract}
Abstrak
Di era digital masyarakat menjadi lupa akan jati diri bangsa, hal tersebut menjadikan masyarakat melupakan nila-nilai Pancasila, akibatnya Indonesia mengalami krisis moral dan etika, khususnya dikalangan anak muda atau generasi muda. Padahal Pancasila adalah pedoman hidup Bangsa Indonesia. Pentingnya edukasi terhadap masyarakat dan generasi muda sejak dini, agar mereka lebih paham dan mengerti tentang pentingnya nilai-nilai Pancasila. Pemberian edukasi dapat dilakukan melalui pendidikan formal dan pendididan nonformal. Pendidikan formal melalui pengajaran yang didapatkan disekolah, sedangkan pendidikan nonformal didapatkan dari keluarga dan masyarakat.
\end{abstract}

\section{Latar Belakang}

Di era globalisasi banyak masyarakat Indonesia lupa akan jati diri bangsanya. Bermacam perubahan yang terjadi, seperti gaya hidup, pola pikir masyarakat, hal tersebut menjadikan masyarakat melupakan nilai-nilai Pancasila. Indonesia saat ini sedang mengalami krisis moral dan etika, khusunya di kalangan remaja atau generasi muda. Semakin majunya teknologi menyebabkan mudah masuknya informasi dan menjadikan dunia seperti tidak memiliki batas, hal tersebut dapat menyebabkan pudarnya nilai-nilai Pancasila. Pentingnya pemberian edukasi bagi masyarakatnya khusunya generasi muda tentang nilai pancasila, persatuan dan kesatuan bangsa, karena mereka adalah generasi penerus bangsa

Langkah yang dapat dilakukan dengan memberikan pengetahuan baik formal dan norformal, formal melalui pendidikan dan nonformal melalaui keluarga dan masyarakat. jika tidak cepat ditangani dengan baik, maka generasi muda dapat melupakan nilai-nilai Pancasila, hal tersebut dapat menyebabkan pudarnya rasa kesatuan dan persatuan bangsa.

Data kasus pelanggaran nilai pancasila diperoleh dari binus.ac.id tingkat kriminalitas di Indonesia mengalami peningkatan. Data Kepolisian RI menunjukkan kenaikan angka kriminalitas pada pekan ke-24 tahun 2020, pada minggu ke-23 dan minggu ke-24 ditahun 2020 mengalami kenaikan gangguan kamtibmas sebesar 38,45 persen. Terdapat 4.244 kasus kriminal yang terjadi pda pekan ke-23, meningkat sebanyak 5.876 kasus pada pekan ke-24 (Halim, 2020). Berikut ini adalah data menurunya sikap nasionalisme berdasarkn hasil penelitian survey statistik pemuda Indonesia dilakukan oleh Badan Pusat Statistik (BPS) tahun 2012, dilakukan di 100 sekolah negeri dan swasta, 59 sekolah swasta dan 41 sekolah negeri. Survei ini dilakukan di Jakarta, Bogor, Bandung, Depok, Bekasi, Tanggerang, Jakarta Selatan, Jakarta Timur, Jakarta Barat, Jakarta Pusat. Sebanyak 993 siswa smp dan sma menjadi contoh penelitian (Rosyada, 2018) 


\section{Kasus/ Masalah}

- Permasalahan apa yang terjadi jika masyarakat kurang mengetahui makna dari nilainilai Pancasila?

- Seberapa penting pemberian edukasi tentang persatuan dan kesatuan bangsa Indonesia bagi pelajar dan juga masyarakat?

- Langkah apa yang dapat diambil untuk meningkatkan rasa persatuan dan kesatuan dalam diri seorang pelajar dan masyarakat?

- Apa faktor penyebab menurunya nilai-nilai Pancasila dalam diri pelajar dan masyarakat?

\section{Tinjauan Pustaka}

Di era globalisasi dimana semua hal yang ada di dunia dapat dengan mudah dijangkau. Di zaman modern manusia mampu menciptakan teknologi canggih yang dapat membantu manusia berkomunikasi dengan manusia lain dengan jarak yang jauh. Hal tersebut menjadikan dunia seakan tidak memiliki batas dan dapat menimbulkan dampak negatif. Masuknya nilai-nilai budaya dari luar dengan mudah diterima oleh masyarakat. Dampak negatif bagi masyarakat adalah perubahan sikap dan perilaku masyarakat Indonesia semakin tidak sesuai dengan nilai pancasila. Masyarakat lebih memilih nilai budaya asing untuk dijadikan pedoman dalam besikap dan berperilaku.

\section{Presentase Menurunya Sikap Nasionalisme Pada Pelajar}

1. Malas mengikuti upacara bendera $: 83.3 \%$

2. Lebih menyukai produk-produk luar negeri $: 73.3 \%$

3. Tidak perduli terhadap masalah bangsa

4. Lebih menyukai sekolah luar negeri

5. Lebih menyukai nama-nama luar negeri

6. Merasa figur-figur barat lebih asik

7. Menggap pancasila tidak relevan sebagai dasar negara Sumber : (Rosyada, 2018)

Data tersebut masih relevan hingga saat ini, salah satu contoh menurunya sikap nasionalisme adalah malas mengikuti upacara yang peresntasinya sebesar $83,3 \%$ relevan dengan hasil pra penelitian yang dilakukan oleh peneliti. Peneliti melakuan penelitian wawancara dengan guru PPkn di SMP 63 Jakarta, masih banyak siswa yang malas, tidak serius dan becanda saat pelaksaan upacara. Hasil tersebut menunjukkan penurunan sikap nasionalisme, para generasi penerus bangsa Indonesia dalam bersikap dan berperilaku tidak mencerminkan nilai-nilai pancasila. Dimana seharusnya sekolah adalah tempat menanamkan nilai-nilai pancasila, tetapi masih banyak ditemukan sikap dan perilaku yang tidak sesuai dengan nilai Pancasila, terutama sila ketiga tentang persatuan Indonesia. Berdasarkan pendapat Sudarmawan, Pancasila merupakan ideologi bangsa Indonesia, merupakan pedoman dan pegangan bagi masyarakat Indonesia untuk melangkah dan bertindak. Seperti yang dikemukakan Winarno (2012:7)

Penanaman pancasila dapat dilakukan melalui pendidikan formal dan juga non formal, pendidikan formal dapat dilakukan di sekolah, dan pendidikan non formal dapat 
dilakukan di lingkungan keluarga dan masyarakat. Pentingnya penanaman nilai pancasila, terlebih sila ketiga agar dapat beradaptasi dengan pengaruh negatif era globalisasi yang banyak bertentangan dengan Pancasila. Strategi yang tepat dalam menyampaikan nilai Pancasila merupakan kunci suksenya pembelajaran tentang nilai-nilai Pancasila.

\section{Pembahasan}

Dari yang kita baca baik dari pandangan umum dan juga secara teori dapat kita bahas bahwa salah satu penyebab menurunya nilai-nilai Pancasila adalah berkembangnya teknologi yang tidak diserati dengan edukasi dan pengetahuan tentang pentingnya nilai-nilai Pancasila. Tetapi hal tersebut dapat diperbaiki dengan memberikan edukasi terhadap masyarakat khusunya generasi muda. Selain faktor eksternal faktor internal juga penting dilakukan, yaitu kesadaran diri sendiri tentang pentingnya kesatuan dan persatuan bangsa.

\section{Kesimpulan}

- Pentingnya edukasi sejak dini kepada masyarakat dan generasi muda

- Pentingnya kesadaran diri terhadap nilai-nilai Pancasila, khususnya persatuan dan kesataun.

- Menggunakan teknologi sebaik mungkin, dan menyaring informasi yang diterima agar sesuai dengan nilai-nilai Pancasila

\section{Daftar pustaka}

Yurisdika, A. D. (2019). Strategi Penanaman Nilai-Nilai Persatuan dan Kesatuan Pada Siswa. Jurnal Rontal Keilmuan Pancasila dan Kewarganegaraan, 5(2).

Lim, M. (2021). Menanamkan Nilai Persatuan Dan Kesatuan Melalui Pembelajaran Sejarah. El Tarikh: Journal of History, Culture and Islamic Civilization, 2(1), 117-128.

Siyoto, S., \& Sodik, M. A. (2015). Dasar metodologi penelitian. Literasi Media Publishing.

Setyani, A. T., \& Sodik, M. A. (2018). Pengaruh Merokok Bagi Remaja Terhadap Perilaku dan Pergaulan Sehari-hari.

Sodik, M. A. (2018, September). Analysis of Improved Attitude of Youth in HIV/AIDS Prevention through the Provision of Health Education with Peer Education. In The 2nd Joint International Conferences (Vol. 2, No. 2, pp. 495-502).

Sodik, M. A., \& Setyani, A. T. (2018). Effect of Smoking For Teens Against Behavior and Social Interaction.

Sodik, M. A. (2014). Sikap Pencegahan Aborsi Ditinjau Dari Pengetahuan Tentang Bahaya Dan Resiko Kesehatan. Strada Jurnal Kesehatan http://publikasi. stikesstrada. ac. id/wpcontent/uploads/2015/02/9-SIKAP-SIKAPPENCEGAHAN-ABORSI. pdf.

Sodik, M. A., Yudhana, A., \& Dwianggimawati, M. S. (2018). Nutritional status and anemia in islamic boarding school adolescent in Kediri City East Java Indonesia. Indonesian Journal of Nutritional Epidemiology and Reproductive, 1(3), 172-176.

TAHIN, M. W., \& Sodik, M. A. (2021). Pengaruh Merokok Bagi Remaja Terhadap Perilaku dan Pergaulan Sehari-hari.

Sodik, M. A., \& Widyastika, K. S. (2020). Analysis Completeness of Outpatient Medical Record Documents Completion Based on Motivation and Compliance with Basic Tasks and The Function of Officers. Journal of Global Research in Public Health, 5(1), 25-31. 
Sodik, M. A., \& Maulina, D. (2021). Analysis Of Android-Based Online Message Gateway Towards The Use Of Plastic Bags On PKK Mother. Journal of Global Research in Public Health, 6(1), 31-37.

Sodik, M. A., Salam, D. M., \& Kardjati, S. (2020). Analysis Of Android-Based Online Message Gateway Towards The Use Of Plastic Bags. STRADA Jurnal IImiah Kesehatan, 9(2), 1657-1664. 